Research paper

\title{
Smoking cessation and depressive symptoms at 1-, 3-, 6-, and 12-months follow-up
}

\author{
Rubén Rodríguez-Cano ${ }^{\mathrm{a}, *}$, Ana López-Durán ${ }^{\mathrm{a}}$, Elena Fernández del Río ${ }^{\mathrm{a}, \mathrm{b}}$, \\ Carmela Martínez-Víspo a ${ }^{a}$ Úrsula Martínez ${ }^{a}$, Elisardo Becoña ${ }^{a}$ \\ a Smoking and Addictive Disorders Unit, Faculty of Psychology, Department of Clinical Psychology and Psychobiology, University of Santiago de Compostela, \\ Spain \\ ${ }^{\mathrm{b}}$ Department of Psychology and Sociology, Faculty of Social Sciences and Work, University of Zaragoza, Spain
}

\section{A R T I C L E I N F O}

\section{Article history:}

Received 11 August 2015

Received in revised form

18 October 2015

Accepted 23 November 2015

\section{Keywords:}

Smoking cessation

Depression

12-months follow-up

Beck Depression Inventory

Relapse

\begin{abstract}
A B S T R A C T
Background: The relationship between tobacco and depressive symptoms has been examined. However, there is little information on the evolution of these symptoms when an individual quits. The aim of this study was to analyze the evolution of depressive symptoms over time (pre-, post-treatment, 1-, 3-, 6-, and 12-months follow-up) in relation to smoking status 12 months after having received a psychological treatment for smoking cessation.

Method: The sample was made up of 242 adults who received cognitive-behavioral treatment for smoking cessation $(64.4 \%$ women; mean age $=41.71$ years $)$. The BDI-II was used to assess depressive symptomatology. Participants were classified into three groups according to smoking status at 12months follow-up (abstainers, relapsers, and smokers).

Results: There were no significant differences in depressive symptoms among the three groups at pretreatment. At the end of treatment, abstainers and relapsers presented less depressive symptomatology than smokers. At follow-up, abstainers continued to present less depressive symptomatology than smokers, whereas in relapsers, symptoms began to increase as the relapses occurred. Regarding the evolution of depressive symptomatology, the abstainer and relapser groups showed a significant reduction at the end of treatment. Only in the group of abstainers did the decrease continue during 12 months follow-up.

Limitations: The decrease of the initial sample size from 562 to 242 participants. Variables such as selfesteem and self-efficacy were not assessed.

Conclusions: Smoking cessation is associated with a decrease in depressive symptomatology, that is maintained over time. In contrast, relapse is associated with an increase of such symptoms. These findings signify the potential importance of addressing depressive symptomatology in smoking cessation treatment.
\end{abstract}

(c) 2015 Published by Elsevier B.V.
With regard to nicotine withdrawal symptoms, which include

\section{Introduction}

The relationship between tobacco consumption and depression is well established (Tsoh et al., 2000) and has been addressed from multiple perspectives in recent years. People with depression are more likely to be smokers (Breslau et al., 1998; Holma et al., 2013; Lasser et al., 2000) and to be nicotine dependent (Dierker and Donny, 2008). The evidence also indicates that smokers have a higher risk of experiencing depression (Bandiera et al., 2015; Breslau and Johnson, 2000; Grant et al., 2004).

\footnotetext{
* Correspondence to: Smoking and Addictive Disorders Unit, University of Santiago de Compostela, Faculty of Psychology, Department of Clinical Psychology and Psychobiology, Campus Vida, 15782 Santiago de Compostela, Spain.
} some depressive-like symptoms (Hughes, 2007b), findings indicate that smokers with a history of depression are more likely to experience depressive symptoms, and of greater severity, in the withdrawal syndrome (Covey et al., 1990; Langdon et al., 2013). In addition, smokers frequently use tobacco to cope with discomfort that these symptoms cause (Leventhal et al., 2013).

People with depression also have more difficulty quitting smoking (Ziedonis et al., 2008) and are more likely to relapse (Brodbeck et al., 2014; Zvolensky et al., 2015). In their meta-analysis, Hitsman et al. (2013) found that the existence of a history of major depression in the past, but not in the present, hinders the achievement of abstinence. In addition, evidence suggests that specific symptoms of depression such as anhedonia and low positive affect predict relapse at follow-up (Leventhal et al., 2008). 
Leventhal et al. (2014) found that life-time anhedonia predicted smoking cessation outcome better than history of depressive disorder and lifetime depressed mood. Further, studies have found that the introduction of cognitive-behavioral mood management techniques significantly improves the effectiveness of smoking cessation interventions (Gierisch et al., 2012). For example, MacPherson et al. (2010), examined the effect of including behavioral activation techniques in a smoking cessation intervention, and found improved abstinence outcomes and decreases in depressive symptomatology.

The findings regarding whether smoking cessation increases the likelihood of depression are inconclusive. Tsoh et al. (2000) found that the likelihood of experiencing depression is similar between those who quit smoking and those who do not, except for those smokers with a previous history of depression, whose risk would be maintained for at least 6 months, according to Glassman et al. (2001). The review by Ragg et al. (2013) indicates that the risk of experiencing depressive symptoms when quitting is not higher in individuals with a history of major depression, because their mood may improve after quitting smoking. Similarly, in a study of smokers with depression, Mathew et al. (2013) found that both those who quit and those who remained abstinent demonstrated significant improvements in psychological functioning compared to those who continued smoking at 3 and 6 months follow-up. The authors note that the increase in depressive symptoms seems to be more closely related to the failure to successfully quit smoking.

In an attempt to explain these discrepancies, Hughes (2007a) notes that the belief that smoking cessation increases depressive symptomatology is due to the attribution that nicotine has antidepressant effects and to the symptomatology associated with the withdrawal syndrome that appears after quitting. However, some research suggests that smokers do not smoke in order to gain the antidepressant effects of smoking and furthermore, depressive symptoms are not the most frequent symptoms when undergoing withdrawal. In fact, with respect to other drugs, the evidence indicates that smoking cessation is related to an improvement of depressive symptoms. Similarly, a recent meta-analysis of longitudinal studies carried out by Taylor et al. (2014) found that both in general and clinical populations (individuals who suffer some mental disorder), smoking cessation is associated with a decrease in depression, anxiety, and stress and an improvement in positive mood and quality of life.

Therefore, the published studies confirm the existence of a clear relationship between smoking and depression, although there are discrepancies between some of the studies about the nature of this relationship and how the variables affect each other. Evaluation of depressive problems at different moments of the process of smoking cessation would help to clarify this relationship, especially taking into account not only the comparison of smokers and abstainers but also including those who initially quit smoking but who relapse later on.

The aim of the present study is to analyze the relationship between depressive symptomatology, assessed with the Beck Depression Inventory-II (BDI-II) at different times (pre-, post-treatment and at 1-, 3-, 6- and 12-months follow-up) and smoking status 12 months after having received a cognitive-behavioral treatment for smoking cessation. To our knowledge, this is the first study that compares depressive symptoms at different times across three groups depending on smoking status at 12 months follow-up: abstainers (those who quit smoking since the end of treatment until 12-months follow-up), smokers (those who never quit smoking), and relapsers (those who quit smoking at the end of treatment but who relapsed before the 12-months follow-up). The hypotheses of this study are: (1) people who quit smoking at the end of treatment and remain abstinent at 12 months have fewer depressive symptoms at all the assessed times (pre-, posttreatment and follow-ups) compared to participants who did not quit smoking and those who relapsed, and (2) as the time without smoking increases, people who remain abstinent at 12 months present a greater decrease of depressive symptoms than smokers and relapsers at all the evaluations performed.

\section{Methods}

\subsection{Participants}

The initial sample consisted of 562 smokers who received cognitive-behavioral treatment for smoking cessation who met the inclusion and exclusion criteria of the study. Inclusion criteria were: aged 18 or over; wishing to participate in the treatment program; and smoking 10 or more cigarettes per day. Exclusion criteria were: a diagnosis of severe mental disorder (bipolar disorder and/or psychotic disorder); concurrent dependence on other substances (alcohol, cannabis, cocaine and/or heroin); having participated in the same or similar treatment over the previous year; having received pharmacological smoking cessation treatment (nicotine replacement therapy, bupropion, varenicline) in the past year; suffering from a physical pathology with a high life risk that would require immediate individual intervention (e.g., recent myocardial infarction); smoking a type of tobacco other than cigarettes (e.g., cigars); and failing to attend the first treatment session. All participants were recruited between 2009 and 2014.

As the aim of this study was to assess depressive symptomatology across all follow-ups, we included only those cases who completed the BDI-II at all times (pre-, post-, and 1-, 3-, 6-, and $12-$ months follow-up). Therefore, the final sample was made up of 242 smokers.

\subsection{Instruments}

\subsubsection{Smoking Habit Questionnaire}

The smokers filled out the 56-item Smoking Habit Questionnaire (Becoña, 1994), designed to gather information both on sociodemographic variables (gender, age, marital status, educational level) and tobacco use (i.e., number of cigarettes smoked per day).

\subsubsection{Fagerström Test for Nicotine Dependence}

(FTND, Heatherton et al., 1991). This scale is made up of 6 items and the scores range from 0 to 10 points. Information related to nicotine dependence was obtained at baseline. In the present sample, the reliability obtained by means of Cronbach's alpha was 0.59 .

\subsubsection{Beck Depression Inventory-II}

(BDI-II; Beck et al., 1996; Sanz and Vázquez, 2011). This is a 21item self-report scale measuring current depressive symptoms. The internal consistency obtained in Spanish sample by Cronbach's alpha was 0.90 .

\subsubsection{Micro+ Smokerlyzer}

(Bedfont Scientific Ltd., Sittingbourne, UK). This was used to measure carbon monoxide ( $\mathrm{CO}$ ) in exhaled air in order to corroborate self-reported abstinence at the end of treatment and at follow-ups (1, 3, 6 and 12 months).

\subsection{Procedure}

The initial assessment of all smokers was carried out in a face- 
Table 1

Demographics, smoking history, and depression variables at pretreatment among smoking status groups at 12 months $(N=242)$.

\begin{tabular}{|c|c|c|c|c|c|c|c|c|c|}
\hline & \multicolumn{2}{|c|}{ Smokers $(n=49)$} & \multicolumn{2}{|c|}{ Relapsers $(n=102)$} & \multicolumn{2}{|c|}{ Abstainers $(n=91)$} & \multirow[t]{2}{*}{$\chi^{2}$} & \multirow[t]{2}{*}{$p$} & \multirow[t]{2}{*}{ Cramer's V } \\
\hline & $n$ & $\%$ & $n$ & $\%$ & $N$ & $\%$ & & & \\
\hline Gender & & & & & & & 0.295 & 0.863 & 0.035 \\
\hline Female & 29 & 59.2 & 65 & 63.7 & 57 & 62.6 & & & \\
\hline Male & 20 & 40.8 & 37 & 36.3 & 34 & 37.4 & & & \\
\hline Marital Status & & & & & & & 3.020 & 0.806 & 0.079 \\
\hline Single & 15 & 30.6 & 39 & 38.3 & 28 & 30.8 & & & \\
\hline Married & 29 & 59.2 & 50 & 49 & 54 & 59.3 & & & \\
\hline Divorced & 4 & 8.2 & 10 & 9.8 & 8 & 8.8 & & & \\
\hline Widowed & 1 & 2 & 3 & 2.9 & 1 & 1.1 & & & \\
\hline Educational Level & & & & & & & 5.996 & 0.199 & 0.111 \\
\hline Basic & 12 & 24.5 & 22 & 21.6 & 22 & 24.2 & & & \\
\hline Middle & 23 & 46.9 & 36 & 35.3 & 26 & 28.6 & & & \\
\hline Higher & 14 & 28.6 & 44 & 43.1 & 43 & 47.2 & & & \\
\hline FTND & & & & & & & $7.115^{\mathrm{a}}$ & 0.029 & 0.171 \\
\hline Total score $<6$ & 21 & 42.9 & 56 & 54.9 & 60 & 65.9 & & & \\
\hline \multirow[t]{2}{*}{ Total score $\geq 6$} & 28 & 57.1 & 46 & 45.1 & 31 & 34.1 & & & \\
\hline & $M$ & $S D$ & $M$ & $S D$ & $M$ & $S D$ & $F$ & $p$ & $\eta^{2}$ \\
\hline Age & 43.86 & 8.85 & 42.04 & 11.44 & 40.20 & 8.95 & 2.366 & 0.114 & 0.018 \\
\hline CPD & 23 & 7.90 & 20.73 & 6.69 & 19.08 & 6.80 & $4.732^{\mathrm{a}}$ & 0.010 & 0.041 \\
\hline BDI-II pre-treat. & 13.12 & 11.31 & 9.45 & 10.20 & 9.33 & 10.27 & 2.488 & 0.085 & 0.020 \\
\hline
\end{tabular}

Note. FTND: Fagerström Test for Nicotine Dependence; CPD: Cigarettes Per Day; BDI-II: Beck Depression Inventory II.

a Significant intergroup differences between Abstainers and Smokers.

to-face interview and the above-described instruments were administered. All the smokers gave their informed consent for participation, and the study was authorized by the Bioethics Committee of the University of Santiago de Compostela. Next, the Smoking Cessation Program (Becoña, 2007), a cognitive-behavioral treatment, was administered in groups of 6-8 participants. This is a standardized and manualized treatment consisting of six sessions (one per week) with the following elements: treatment contract, self-report and graphic representation of cigarette consumption, information about tobacco, stimulus control, activities for the avoidance of withdrawal syndrome, physiological feedback (CO in exhaled air) on cigarette consumption, nicotine fading (change of cigarette brands each week progressively decreasing the intake of nicotine and tar), and relapse-prevention strategies.

There was a face-to-face follow-up 1, 3, 6, and 12 months after treatment. Self-reported abstinence at the end of treatment and at each follow up was assessed by $\mathrm{CO}$ in exhaled air $(\mathrm{CO}<10 \mathrm{ppm})$. Biochemically validated smoking status was used rather than selfreported smoking status. Participants did not use pharmacological smoking cessation treatment during the Smoking Cessation Program or during follow-up.

The criteria used for point-prevalence abstinence at the end of treatment was not smoking in the past $24 \mathrm{~h}$; at 1 and 3 months follow-up point prevalence abstinence was defined as not smoking in the past 7 days and at 6 and 12 months follow-up not smoking in the past 30 days. A participant presenting continuous abstinence at the 12-months follow-up (not having smoked, not even a puff since the end of treatment) was considered to belong to the abstainer group. Those who did not quit smoking at the end of treatment and continued smoking during the follow-ups were considered smokers, and those who stopped smoking at the end of the treatment but were smoking during follow-up were considered relapsers (West et al., 2005).

\subsection{Statistical analysis}

To examine possible differences as a function of smoking status at 12 months (smokers, relapsers, and abstainers) in demographic and tobacco consumption variables and pretreatment depressive symptomatology, we used chi-square and Snedecor's $F$. To determine the effect size, we used Cramer's $V$ and eta-square, respectively.

Mean scores in depressive symptoms were compared among the three groups (smokers, relapsers, and abstainers) at all times (pre- and posttreatment and of 1-, 3-, 6- and 12-months followups) and a one factor ANOVA was carried out. For post hoc comparisons, we used the Bonferroni method. To correct the absence of homoscedasticity, we applied a correction of $\mathrm{F}$ (Brown-Forsythe F - Brown and Forsythe, 1974). For post hoc analysis of the BrownForsythe F, we used Games-Howell's method (Games and Howell, 1976).

To assess longitudinal changes in depressive symptoms within subjects in each of the three groups, we used a repeated measures ANOVA. The repeated measures factor was the BDI-II score at preand posttreatment and at 1-, 3-, 6- and 12-months follow-up. We used the Greenhouse-Geisser $F\left(F_{\mathrm{GG}}\right)$ to correct for the absence of sphericity, in order to accommodate more general covariance structures for the repeated measures (Greenhouse and Geisser, 1959). Post hoc analyses were performed with the Bonferroni test.

Analyses were performed with the SPSS 20, and the statistical significance level was set at $\leq 0.05$.

\section{Results}

The average age of participants was 41.71 years $(S D=10.11)$; $37.6 \%$ of the sample were male and $62.4 \%$ female. The average number of cigarettes smoked per day was $20.57(S D=7.11) ; 41.7 \%$ had higher education and more than one half (55\%) were married or living as a couple. The mean nicotine dependence score (according to the Fagerström Test for Nicotine Dependence - FTND) was $5.13(S D=2.08)$.

At the end of treatment, $79.8 \%$ of the participants $(\mathrm{N}=242)$ had quit smoking. For this study, we divided the sample into three groups, as a function of the participants' smoking status at 12 months: smokers $(n=49)$, abstainers $(n=91)$, and relapsers $(n=102)$. Fifty-two percent $(n=53)$ of participants in the relapser group had relapsed before the 3-month follow-up.

We found no significant differences as a function of sociodemographic characteristics (age, gender, marital status, and level of education) or in pretreatment BDI-II scores among the three groups. We found significant differences at pretreatment between 
Table 2

Mean scores on the Beck Depression Inventory according to time (treatment and follow-ups) and smoking status at 12-months follow-up.

\begin{tabular}{|c|c|c|c|c|c|c|c|c|c|}
\hline & \multicolumn{2}{|c|}{ Smokers $(n=49)$} & \multicolumn{2}{|c|}{ Relapsers $(n=102)$} & \multicolumn{2}{|c|}{ Abstainers $(n=91)$} & \multirow[t]{2}{*}{$F$} & \multirow[t]{2}{*}{$p$} & \multirow[t]{2}{*}{$\eta^{2}$} \\
\hline & $M$ & $S D$ & $M$ & $S D$ & $M$ & $S D$ & & & \\
\hline \multicolumn{10}{|l|}{ Time } \\
\hline Pre-treatment & 13.12 & 11.31 & 9.45 & 10.20 & 9.33 & 10.27 & 2.488 & .085 & .020 \\
\hline Post-treatment & 11.90 & 12.32 & 6.76 & 6.24 & 6.31 & 7.65 & 6.263 & .003 & .064 \\
\hline \multicolumn{10}{|l|}{ Follow-ups } \\
\hline 1 month & 11.02 & 10.79 & 7.12 & 8.96 & 5.84 & 6.76 & 5.203 & .007 & .047 \\
\hline 3 months & 12.04 & 12.37 & 7.77 & 8.73 & 4.41 & 5.68 & 10.118 & .001 & .095 \\
\hline 6 months & 12.84 & 11.90 & 7.99 & 9.40 & 4.62 & 7.15 & 11.060 & .001 & .096 \\
\hline 12 months & 10.78 & 11.70 & 8.80 & 10.03 & 4.54 & 6.31 & 7.774 & .001 & .069 \\
\hline
\end{tabular}

abstainers and smokers in the FTND $\left(\chi^{2}=7.115, p<.05\right)$ and the number of cigarettes/day pretreatment $(F=4.732, p<0.01)$ (see Table 1).

\subsection{Smoking status at the 12-months follow-up and depression across time (pre- and posttreatment and follow-ups)}

As shown in Table 2, abstainers had a lower BDI-II score at the end of treatment and at all follow-ups than smokers. Abstainers also presented fewer depressive symptoms than relapsers, but only at the 3-, 6-, and 12-months follow-ups. Additionally, we also found that the relapser group scored significantly lower in the BDI-II than the smokers at the end of treatment and at 6-month follow-up.

\subsection{Evolution of depression from pretreatment to 12-months follow- up}

Regarding the evolution of depressive symptomatology, the repeated measures analysis yielded differences in depressive symptoms over time as a function of smoking status at 12 months $\left[F_{\mathrm{GG}}(8.68,1032.80)=3.205, p=0.001, \eta^{2}=0.026\right]$, adjusting for nicotine dependence $\left(F_{\mathrm{GG}}, p>.05\right)$. Therefore, the means presented within the group are estimated means after including these covariates (see Fig. 1).

Post-hoc comparisons show that the abstainers' group was the only one that presented significant differences at the end of treatment and at all follow-ups in comparison to pretreatment assessment. As time went by without smoking, their depressive symptomatology decreased, and the most important reduction occurred at the 3-month follow-up (5.04 marginal points)

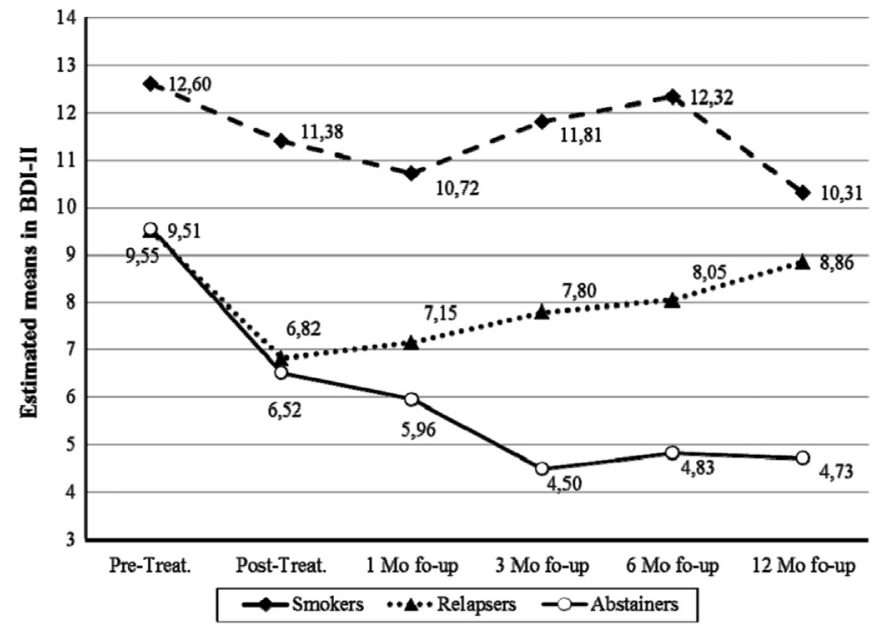

Fig. 1. Estimated means in depression (BDI-II) according to time and smoking status at 12 months, adjusting for nicotine dependence $(N=242)$. compared to the pretreatment assessment.

The group of relapsers only presented significant differences between the pre- and post-treatment assessments. As soon as they quit smoking, the depressive symptoms decreased, but these differences disappeared when relapses occurred. In the group of smokers there were no significant differences in depressive symptomatology either at the initial level, at the end of treatment, or at follow-up.

\section{Discussion}

The present study aimed to analyze the relationship between the evolution of depressive symptoms and smoking status at 12 months follow-up in smokers who received a cognitive-behavioral treatment for smoking cessation. The presence of depressive symptoms as measured with the BDI-II was assessed at different times (pre-, post-treatment, and at 1-, 3-, 6-, and 12-months follow-ups).

Differences in terms of sociodemographic characteristics (age, gender, marital status and level of education) among the three groups were not found. Berlin et al. (2010) did not find differences between abstinent and smokers in age, gender and depression at baseline characteristics either. In reference to depressive symptoms scores, we have not reached differences in the BDI-II scores at baseline. In this sense, Kahler et al. (2002) showed that smokers who were abstinent had lower BDI-II scores at baseline than smokers however, they also concluded that giving up smoking provokes a decrease in depressive symptoms.

The first hypothesis, that people who quit smoking and remain abstinent at 12 months have fewer depressive symptoms at all assessment times was partially supported.

The results showed that the group of abstainers had fewer depressive symptoms than the other two groups at all times analyzed, except for the pretreatment assessment, where we found no significant differences. That is, the depressive symptoms they presented when initiating the smoking cessation treatment did not determine treatment success either at the short or the long term. Previous studies suggesting that people with depression have more difficulty quitting and a higher likelihood of relapse (i.e., Ziedonis et al., 2008; Zvolensky et al., 2015). Also, Leventhal et al. (2014) showed that lifetime depressive symptoms are associated with continuing to smoke. There may be other variables such as the existence of a history of depression in the past, as indicated by Hitsman et al. (2013), which determine treatment outcome, so that the presence of this type of symptoms should not be an obstacle for people to start a smoking cessation treatment and to succeed in it.

In the remaining evaluations (post-treatment and follow-ups), people who quit smoking and remained abstinent at 12 months had significantly lower scores in depressive symptomatology 
compared with people who did not quit smoking. In a sample of patients with chronic depressive disorder, Mathew et al. (2013) found that smokers who achieved prolonged abstinence showed decreased levels of affective symptoms at 6 months follow up. Therefore, quitting smoking may be associated with improvements in mood (Taylor et al., 2014) or at the very least does not result in an increase in depressive symptoms Capron et al. (2014). Conversely, previous studies show that depressive symptoms increase after quitting smoking due to the loss of the antidepressant effects of nicotine or to nicotine withdrawal (Hughes, 2007b). Another outcome that supports the importance of smoking cessation for mood improvement is that the relapser group increased their scores in depression in comparison with the group of abstainers as of the 3-month follow-up (up to that time, the scores were similar). This period has been shown as the most likely for smoking relapse (Piñeiro et al., 2014). Berlin et al. (2010) showed that smokers who relapse exhibited an increase in depression and anxiety symptoms, as well as suicidal ideation. As pointed out by Zvolensky et al. (2015), further investigations must examine whether the increase in depressive symptoms leads to relapse or whether, on the contrary, after a relapse there is an increase in depressive symptoms due to, for example, reduction of selfefficacy.

The results of this study support the second hypothesis. In the group that remained abstinent at 12 months follow-up, there was a gradual decrease of depressive symptomatology from pretreatment until the 12 months follow-up. In the groups of smokers and relapsers, only at the end of treatment was there an improvement of symptoms. This decrease produced during treatment in all the groups might be due to the fact that the treatment includes psychological strategies that may also be useful for mood management (e.g., problem solving, stress management), but after completing the treatment or if there is a relapse, these positive effects on mood disappear.

Ischaki and Gratziou (2009) and Brodbeck et al. (2014) point to self-efficacy and self-esteem as mediating variables between depression and smoking cessation. Compared with relapsers or with those who never stopped smoking, those who remain abstinentdespite not differing in depression scores at the beginning of treatment-probably use the strategies to maintain abstinence that they learned throughout the treatment, thereby increasing their self-efficacy and the likelihood of not relapsing (Marlatt and Donovan, 2005).

This study allows us to conclude that people who quit smoking by means of a cognitive behavioral treatment present a decrease in depressive symptomatology that is maintained if they do not relapse. The mood management strategies that are used in the treatment may be decisive, not only to increase the probability of smoking cessation but also to improve mood; hence, the importance of including them in treatments regardless of whether or not depression is present (Brown et al., 2001; Haas et al., 2004; MacPherson et al., 2010). Even though in the current study, the mean depression scores within the group of abstainers are within the normal range at pretreatment and 12 months follow up, pre2 vious studies including Lenventhal et al. (2014) and Niaura et al. (2001) have shown that lower level depressive symptoms can predict treatment outcomes. For this reason our results have a clinical significance for smoking treatment. Therefore, we can also conclude that smoking cessation is recommended even in those people who were previously thought to have difficulties due to presenting depressive problems.

\subsection{Limitations and future directions}

Among the limitations of the present study, we highlight the decrease of the initial sample size from 562 to 242 participants, as we could only use those smokers of whom we had BDI-II data at all the assessment times. However, we point out that this is the first study to perform an assessment of depressive symptoms at different key periods of the cessation process and during the period of greatest risk of relapse. A second limitation is that variables such as self-esteem and self-efficacy were not assessed within the current study. These variables could be relevant in explaining the relationship between depression and smoking cessation. However, as noted above, this opens new lines of research to continue working.

Among the strengths of this study, we note that, in addition to performing an assessment of the evolution of depressive symptoms, we took into account not only the group of abstainers and the group of smokers but also a group of the people who relapsed after quitting. In addition, we used the most restrictive abstinence criterion, continuous abstinence, which allows more accurate interpretation of the results obtained (West et al., 2005).

As stated by Berlin et al. (2009), the relationship between smoking cessation and depression is complex. Further studies conducted with people with past or current symptoms of depression are needed as there are few studies within this area (Weinberger et al., 2013). This study provides useful information on what occurs after treatment and at follow-up regarding the evolution of depressive symptoms and the benefits that smoking cessation may have on mood.

\section{Contributors}

EB, AL, EFR, RRC, CM and UM designed the study and wrote the protocol. RRC, ALD, EFR, CM, UM and EB obtained the data. RRC, EB, AN and EFR conducted the statistical analysis and contributed to the interpretation of the data. RRC, EB, ALD, EFR drafted the manuscript. CM, UM provided feedback. All authors contributed to and have approved the final manuscript.

\section{Declaration of interests}

There are none.

\section{Acknowledgments}

This research was supported by the Spanish Ministerio de Ciencia y Competitividad (Project reference: PSI2012-31196) and by FEDER (European Regional Development Fund).

\section{References}

Bandiera, F.C., Arguelles, W., Gellman, M., Castañeda, S.F., Barnhart, J., Gonzalez, P., Navas-Nacher, E., Salgado, H., Talavera, G., Schneiderman, N., Lee, D.J., 2015. Cigarette smoking and depressive symptoms among Hispanic/Latino adults: results from the Hispanic Community Health Study/Study of Latinos (HCHS/ SOL). Nicotine Tob. Res. 17, 727-734.

Beck, A.T., Steer, R.A., Brown, G.K., 1996. Manual for the Beck Depression InventoryII. Psychological Corporation, San Antonio, TX.

Becoña, E., 1994. Evaluación de la conducta de fumar [Assessment of smoking behavior]. In: Graña, J.L. (Ed.), Conductas adictivas: Teoría, evaluación y tratamiento. Debate, Madrid, pp. 403-454.

Becoña, E., 2007. Programa para Dejar de Fumar [Smoking cessation program]. Nova Galicia Edicións, Vigo, Spain.

Berlin, I., Covey, L.S., Glassman, A.H., 2009. Smoking and depression: a co-morbidity. J. Dual Diagn. 5, 149-158.

Berlin, I., Chen, H., Covey, L.S., 2010. Depressive mood, suicide ideation and anxiety in smokers who do and smokers who do not manage to stop smoking after a target quit day. Addiction 105, 2209-2216.

Breslau, N., Johnson, E.O., 2000. Predicting smoking cessation and major depression in nicotine-dependent smokers. Am. J. Public Health 90, 1122-1127.

Breslau, N., Peterson, E.L., Schultz, L.R., Chilcoat, H.D., Andreski, P., 1998. Major depression and stages of smoking. A longitudinal investigation. Arch. Gen. 
Psychiatry 55, 161-166.

Brodbeck, J., Bachmann, M.S., Brown, A., Znoj, H.J., 2014. Effects of depressive symptoms on antecedents of lapses during a smoking cessation attempt: an ecological momentary assessment study. Addiction 109, 1363-1370.

Brown, M.B., Forsythe, A.B., 1974. The ANOVA and multiple comparisons for data with heterogeneous variances. Biometrics 30, 719-724.

Brown, R.A., Kahler, C.W., Niaura, R., Abrams, D.B., Sales, S.D., Ramsey, S.E., Goldstein, M.G., Burgess, E.S., Miller, I.W., 2001. Cognitive-behavioral treatment for depression in smoking cessation. J. Consult. Clin. Psychol. 69, 471-480.

Capron, D.W., Allan, N.P., Norr, A.M., Zvolensky, M.J., Schmidt, N.B., 2014. The effect of successful and unsuccessful smoking cessation on short-term anxiety, depression, and suicidality. Addict. Behav. 39, 782-788.

Covey, L.S., Glassman, A.H., Stetner, F., 1990. Depression and depressive symptoms in smoking cessation. Compr. Psychiatry $31,350-354$.

Dierker, L., Donny, E., 2008. The role of psychiatric disorders in the relationship between cigarette smoking and DSM-IV nicotine dependence among young adults. Nicotine Tob. Res. 10, 439-446.

Games, P.A., Howell, J.F., 1976. Pairwise multiple comparison procedures with unequal n's and/or variances: a Monte Carlo study. J. Educ. Stat. 1, 113-125.

Gierisch, J.M. Bastian, L.A., Calhoun, P.S., McDuffie, J.R., Williams, J.W., 2012. Smoking cessation interventions for patients with depression: a systematic review and meta-analysis. J. Gen. Intern. Med. 27, 351-360.

Glassman, A.H., Covey, L.S., Stetner, F., Rivelli, S., 2001. Smoking cessation and the course of major depression: a follow-up study. Lancet 357, 1929-1932.

Grant, B.F., Hasin, D.S., Chou, S.P., Stinson, F.S., Dawson, D.A., 2004. Nicotine dependence and psychiatric disorders in the United States: Results from the national epidemiologic survey on alcohol and related conditions. Arch. Gen. Psychiatry 61, 1107-1115.

Greenhouse, S.W., Geisser, S., 1959. On methods in the analysis of profile data. Psychometrika 32, 95-112.

Haas, A.L., Munoz, R.F., Humfleet, G.L., Reus, V.I., Hall, S.M., 2004. Influences of mood, depression history, and treatment modality on outcomes in smoking cessation. J. Consult. Clin. Psychol. 72, 563-570.

Heatherton, T.F., Kozlowski, L.T., Frecker, R.C., Fagerström, K.O., 1991. The fagerström test for nicotine dependence: a revision of the fagerström tolerance questionnaire. Br. J. Addict. 86, 1119-1127.

Hitsman, B., Papandonatos, G.D., McChargue, D.E., DeMott, A., Herrera, M.J., Spring B., Borrel, B., Niaura, R., 2013. Past major depression and smoking cessation outcome: a systematic review and meta-analysis update. Addiction 108, 294-306.

Holma, I.A., Holma, K.M., Melartin, T.K., Ketokivi, M., Isometsa, E.T., 2013. Depression and smoking: a 5-year prospective study of patients with major depressive disorder. Depress. Anxiety. 30, 580-588.

Hughes, J.R., 2007a. Depression during tobacco abstinence. Nicotine Tob. Res. 9, 443-446.

Hughes, J.R., 2007b. Effects of abstinence from tobacco: valid symptoms and time course. Nicotine Tob. Res. 9, 315-327.

Ischaki, E., Gratziou, C., 2009. Smoking and depression: is smoking cessation effective? Ther. Adv. Respir. Dis. 3, 31-38.

Kahler, C.W., Brown, R.A., Ramsey, S.E., Niaura, R., Abrams, D., Goldstein, M., Mueller, T., Miller, I., 2002. Negative mood, depressive symptoms, and major depression after smoking cessation treatment in smokers with a history of major depressive disorder. J. Abnorm. Psychol. 111, 670-675.
Langdon, K.J., Leventhal, A.M., Stewart, S., Rosenfield, D., Steeves, D., Zvolensky, M.J. 2013. Anhedonia and anxiety sensitivity: prospective relationships to nicotine withdrawal symptoms during smoking cessation. J. Stud. Alcohol Drugs 76, 469-478.

Lasser, K., Boyd, J.W., Woolhandler, S., Himmelstein, D.U., McCormick, D., Bor, D.H., 2000. Smoking and mental illness: a population-based prevalence study. JAMA 284, 2606-2610.

Leventhal, A.M., Ramsey, S.E., Brown, R.A., LaChance, H.R., Kahler, C.W., 2008. Dimensions of depressive symptoms and smoking cessation. Nicotine Tob. Res. 10, 507-517.

Leventhal, A.M., Ameringer, K.J., Osborn, E., Zvolensky, M.J., Langdon, K.J., 2013. Anxiety and depressive symptoms and affective patterns of tobacco withdrawal. Drug. Alcohol Depend. 133, 324-329.

Leventhal, A.M., Piper, M.E., Japuntich, S.J., Baker, T.B., Cook, J.W., 2014. Anhedonia, depressed mood, and smoking cessation outcome. J. Consult. Clin. Psychol. 82 122-129.

MacPherson, L., Tull, M.T., Matusiewicz, A.K., Rodman, S., Strong, D.R., Kahler, C.W. Hopko, D.R., Zvolensky, M.J., Brown, R.A., Lejuez, C.W., 2010. Randomized controlled trial of behavioral activation smoking cessation treatment for smokers with elevated depressive symptoms. J. Consult. Clin. Psychol. 78, 55-61.

Marlatt, G.A., Donovan, D.M., 2005. Relapse Prevention: Maintenance Strategies in the Treatment of Addictive Behaviors, second ed. Guilford Press, New York.

Mathew, A.R., Robinson, J.D., Norton, P.J., Cinciripini, P.M., Brown, R.A., Blalock, J.A., 2013. Affective trajectories before and after a quit attempt among smokers with current depressive disorders. Nicotine Tob. Res. 15, 1807-1815.

Niaura, R., Britt, D.M., Shadel, W.G., Goldstein, M., Abrams, D., Brown, R., 2001. Symptoms of depression and survival experience among three samples of smokers trying to quit. Psychol. Addict. Behav. 15, 13-17.

Piñeiro, B., López-Durán, A., Fernández del Río, E., Martínez, U., Brandon., T.H., Becoña, E., 2014. Craving and nicotine withdrawal in a Spanish smoking cessation sample. Adicciones 26, 230-237.

Ragg, M., Gordon, R., Ahmed, T., Allan, J., 2013. The impact of smoking cessation on schizophrenia and major depression. Australas. Psychiatry 21, 238-245.

Sanz, J., Vázquez, C., 2011. BDI-II: Inventario de Depresión de Beck-II: Manual. Pearson, Madrid.

Taylor, G., McNeill, A., Girling, A., Farley, A., Lindson-Hawley, N., Aveyard, P., 2014. Change in mental health after smoking cessation: systematic review and metaanalysis. BMJ 348, 1151.

Tsoh, J.Y., Humfleet, G.L., Muñoz, R.F., Reus, V.I., Hartz, D.T., Hall, S.M., 2000. Development of major depression after treatment for smoking cessation. Am. J. Psychiatry 157, 368-374.

Weinberger, A.H., Mazure, C.M., Morlett, A., McKee, S.A., 2013. Two decades of smoking cessation treatment research on smokers with depression: 19902010. Nicotine Tob. Res. 15, 1014-1031.

West, R., Hajek, P., Stead, L., Stapleton, J., 2005. Outcome criteria in smoking cessation trials: Proposal for a common standard. Addiction 100, 299-303.

Ziedonis, D., Hitsman, B., Beckham, J.C., Zvolensky, M.J., Adler, L.E., AudrainMcGovern, J., Breslau, N., Brown, R.A., George, T.P., Williams, J., Clahoun, P.S., Riley, W.T., 2008. Tobacco use and cessation in psychiatric disorders: National Institute of Mental Health Report. Nicotine Tob. Res. 10, 1691-1715.

Zvolensky, M.J., Bakhshaie, J., Sheffer, C., Perez, A., Goodwin, R.D., 2015. Major depressive disorder and smoking relapse among adults in the United States: a 10year, prospective investigation. Psychiatry Res. 226, 73-77. 